\title{
Concurrent Use of Herbal and Orthodox Medicines among Residents of Tamale, Northern Ghana, Who Patronize Hospitals and Herbal Clinics
}

\author{
Evans Paul Kwame Ameade $\mathbb{D}^{1},{ }^{1}$ Mohammed Ibrahim, ${ }^{2}$ Halimatu-Sadia Ibrahim, ${ }^{2}$ \\ Rabiatu Hamisu Habib, ${ }^{2}$ and Stephen Yao Gbedema ${ }^{3}$ \\ ${ }^{1}$ Department of Pharmacology, School of Medicine and Health Sciences, University for Development Studies, Tamale, Ghana \\ ${ }^{2}$ Department of Nursing, School of Allied Health Sciences, University for Development Studies, Tamale, Ghana \\ ${ }^{3}$ Department of Herbal Medicine, Faculty of Pharmacy and Pharmaceutical Sciences, Kwame Nkrumah University of \\ Science and Technology, Kumasi, Ghana
}

Correspondence should be addressed to Evans Paul Kwame Ameade; sokpesh@yahoo.com

Received 18 October 2017; Revised 10 January 2018; Accepted 6 February 2018; Published 19 March 2018

Academic Editor: Vincenzo De Feo

Copyright (C) 2018 Evans Paul Kwame Ameade et al. This is an open access article distributed under the Creative Commons Attribution License, which permits unrestricted use, distribution, and reproduction in any medium, provided the original work is properly cited.

\begin{abstract}
Despite the development of more researched and formulated orthodox medicines, herbal medicines continue to be well patronized for persons across the world with some patrons concurrently using both forms, oblivious of the unwanted effects that may occur. Using a multistage sampling procedure, a semistructured questionnaire was used to collect data in April 2016 from 240 informants from three selected hospitals and three herbal clinics in Tamale, a city in northern Ghana. Using Statistical Package for the Social Sciences, binary logistic regression was used to determine sociodemographic predictors of concurrent use of herbal and orthodox medicines. Orthodox medicines were the drug of choice for $54.2 \%$ and $49.2 \%$ of patrons of hospitals and herbal clinics, respectively. Also, $67.5 \%$ of herbal clinic patrons used orthodox medicines, while $25.0 \%$ of hospital attendees used herbal medications prior to their visit to the health facilities. Up to $17.9 \%$ of respondents concurrently used herbal and orthodox medicines for their prevailing ailment with age, less than 30 years being the only predictor of this habit ( $p=0.015 ; 95 \% \mathrm{CI}, 1.183-4.793 ; \mathrm{cOR}=2.4)$. All health professionals including those in herbal clinics should therefore be interested in the drug history of their clients.
\end{abstract}

\section{Background to the Study}

Diseases have afflicted man for ages but humans always make effort to remedy the situation in order to regain a life disturbed by these ailments. The earliest form of healing substances had been herbal medicines, but with the advent of civilization which had led to better scientific understanding of diseases and medications, orthodox medicines have become the main and well recognized products for the management of diseases in modern health systems $[1,2]$. According to Mahomoodally (2013), herbal medicines (HM) include herbs, herbal materials, herbal preparations, and finished products that contain parts of plants or other plant materials as active ingredients [3]. Orthodox medicines (OM) or drugs on the other hand are chemically pure substances which when administered into the body produce pharmacological effects which may consequently lead to alleviation of the disease or help in the diagnosis or prevention of the disorder [4]. Many current orthodox drugs have their origin from herbal medicines, but the main difference between the two is that the herbal drugs contain a large number of compounds, rather than a single pharmacologically active substance; hence components of both herbal and orthodox medicines may act on one another to moderate, oppose, or enhance an effect $[5,6]$. It would have been expected that orthodox medicine should be an overwhelming favoured choice of treatment of diseases since it is a more refined and scientifically studied remedy. Herbal medicines however also continue to be well patronized in both developing and developed countries of the world. According to the World Health Organization (2002), despite the introduction of orthodox medicine by the Europeans who colonized Africa, up to $80 \%$ of Africans still 
use traditional medicines, especially herbal medicine for their primary healthcare needs [7]. Patronage of herbal products has also seen an increase even in developed countries such that approximately $20 \%$ of people in the United States of America use herbal products for various health reasons [8]. Despite the high patronage of herbal medicines all over the world, patients do not inform their doctors about their use of orthodox medicine concurrently with these herbal products and also most doctors do not also enquire from the patients about the use of herbal products during consultation [9-12]. Concurrent use of herbal and orthodox medicines according to Neustadt (2006) causes interactions between these two forms of medicines which can lead to undesirable pharmacokinetic and pharmacodynamic effects [13]. For example, when a herbal preparation containing St. John's Wort (Hypericum perforatum) is administered together with digoxin, there is always a significant decrease in maximum serum concentration of digoxin and hence its efficacy because the plant product increases digoxin metabolism. Again, the anticoagulant effect of warfarin is enhanced when taken together with ginkgo (Ginkgo biloba), thereby increasing the possibility of excessive bleeding $[1,13]$. Issues of adverse effects and drug-herb interactions should be of important public health concerns because of their overall effect on human health and safety. In Ghana, efforts are being made to integrate herbal medicines into the orthodox health facilities to provide alternative system for individuals who for some reasons would want to access alternative medicines for their healthcare needs. The operationalization of the Traditional Medicine Practice Council (TMPC) in 2010 following the passing of the Traditional medicine practice Act, Act 575 in 2000 , and the subsequent commencement of training of medical herbalists by Kwame Nkrumah University of Science and Technology in Ghana in 2001 had accelerated the integration of herbal medicine into the Ghanaian orthodox health system [14]. Beside the herbal clinics in some teaching and regional hospitals, there are privately owned herbal clinics that provide alternative healthcare systems to Ghanaians. These herbal clinics give their clients herbal products. Just as persons who attend orthodox hospitals are given orthodox drugs which could be concurrently taken with herbal medicines, those who patronize herbal clinics would possibly be taking these herbal products with some orthodox medicines as well. Most studies on the concomitant use of herbal and orthodox medicines were carried out in hospitals or communities where orthodox medicines are prescribed for patient or individuals who self-medicate with them [15-18]. There is currently paucity of information on whether persons who visit the herbal clinics also concurrently use orthodox medicines; hence this study assessed the level of concurrent usage of herbal and orthodox medicine among patients at hospitals and herbal clinics in Tamale and ascertained the predictors of this habit among the respondents.

\section{Method}

2.1. Study Design and Setting. A cross-sectional survey to collect data on the level of concurrent usage of herbal medicines and orthodox medicines was undertaken in three public hospitals and the three most patronized herbal clinics in Tamale, a city in northern Ghana which according to the Ghana Statistical Service (GSS) 2010 population and housing census has a total population of 223,252 [19]. The hospitals surveyed were the Tamale Teaching Hospital, Tamale West Hospital, and Tamale Central hospital, while the herbal clinics were Alive Legacy Herbal Clinic, Ameen Scientific Herbal clinic, and Unique Naturalist Herbal Clinic.

2.2. Study Tool. The study was conducted in April 2016 using a semi-structured questionnaire. The questionnaire was pretested among 20 clients, which ensured the correction of ambiguous and inconsistent questions before it was administered for the actual data collection. The authors reviewed the questionnaire to ensure face validity of the data collecting tool. Though most of the final questionnaires were selfadministered, a few were administered employing the faceto-face interview questionnaire administration method with respondents and retrieved immediately after completing the questions. The face-to-face interview questionnaire was used for respondents who were not literate enough to complete the questionnaire on their own.

2.3. Study Sample Size Determination. Cochran's (1977) formula was used to estimate a desirable sample size. The sample size was calculated as follows: $n=z^{2}(1-p) p / d^{2}$, where $n$ is the sample size, $z$ is the standard normal distribution taken as $1.96, p$ is the estimated prevalence rate of herbal users being $80 \%(0.80)$, and $d$ is the margin of error equal to 0.05 . $n=1.96^{2}(1-0.8) 0.8 / 0.05^{2}$; therefore, the minimum sample size for this study was $245.9=246$.

2.4. Sampling Procedure. The sampling method that was employed in this study was the multistage sampling procedure. The first stage consisted of two clusters, named A and B. Cluster A represented those who attend herbal clinics and cluster B represented those who attend hospitals. Respondents in B were outpatients and inpatients, while respondents in A were all outpatients, since A study sites do not have inpatients services. In the second stage, a convenient sampling method was applied with the numbers for each facility apportioned based on the daily attendance records. The sample was divided among clusters A and B in a ratio of $1: 1$.

2.5. Statistical Analysis. The data collected was grouped for editing and keyed into Microsoft Excel (2013 version). Data was analyzed using Statistical Package for the Social Sciences (SPSS), version 20 (SPSS Inc, IBM, Chicago, IL, USA). Association between variables was determined using binary logistic regression. Statistical significance was assumed at $p<$ 0.05 at a confidence interval of $95 \%$.

\section{Results}

3.1. Sociodemographic Profile of Respondents. Table 1 shows the sociodemographic characteristics of respondents in this study. The majority were as follows: females, 127 (52.9\%), followers of the Islamic religion, 154 (64.2\%), those who grew up in rural areas of Ghana, 122 (50.8\%), and persons in the 
TABLE 1: Sociodemographic characteristics of respondents.

\begin{tabular}{|c|c|c|c|}
\hline Variable & Subgroup & Frequency & Percentage \\
\hline \multirow{2}{*}{ Sex } & Female & 127 & 52.9 \\
\hline & Male & 111 & 46.3 \\
\hline \multirow{3}{*}{ Religion } & Christianity & 80 & 33.3 \\
\hline & Islam & 154 & 64.2 \\
\hline & Traditionalist & 3 & 1.3 \\
\hline \multirow{6}{*}{ Age } & $<21$ & 14 & 5.8 \\
\hline & $21-30$ & 104 & 43.3 \\
\hline & $31-40$ & 42 & 17.5 \\
\hline & $41-50$ & 33 & 13.8 \\
\hline & $51-60$ & 21 & 8.8 \\
\hline & $>60$ & 25 & 10.4 \\
\hline \multirow{3}{*}{ Marital status } & Single & 91 & 37.9 \\
\hline & Currently married & 111 & 46.3 \\
\hline & Ever married & 30 & 12.5 \\
\hline \multirow{4}{*}{ Educational status } & None & 74 & 30.8 \\
\hline & Basic & 25 & 10.4 \\
\hline & Secondary/technical & 52 & 21.7 \\
\hline & Tertiary & 73 & 30.4 \\
\hline \multirow{2}{*}{ Location of growing up } & Rural & 117 & 48.8 \\
\hline & Urban & 122 & 50.8 \\
\hline \multirow{7}{*}{ Employment status } & Unemployed & 30 & 12.5 \\
\hline & Students & 45 & 18.8 \\
\hline & Housewife & 24 & 10.0 \\
\hline & Private sector & 20 & 8.3 \\
\hline & Self-employed & 89 & 37.1 \\
\hline & Public sector & 28 & 11.7 \\
\hline & Retiree & 2 & 0.8 \\
\hline \multirow{4}{*}{ Type of accommodation currently occupied* } & Single room in compound house & 132 & 55.0 \\
\hline & Chamber and hall in compound house & 65 & 27.1 \\
\hline & Self-contained apartment & 36 & 15.0 \\
\hline & Mansion & 4 & 1.7 \\
\hline
\end{tabular}

${ }^{*}$ Used as proxy to measure income level. Low income earners occupied single rooms and chamber and hall apartments. Those in self-contained apartments and mansions were middle to high income earners.

low-income bracket, 132 (55.0\%), as indicated by their living accommodation being single rooms in a compound house. Most respondents were between 21 and 30 years old, 104 (43.3\%); currently married, 111 (46.3\%); and self-employed, $89(37.1 \%)$, and had tertiary level education, $73(30.4 \%)$.

\subsection{Reasons for Concurrent Usage of Herbal and Orthodox} Medicines. The level of concurrent usage of herbal medicines and orthodox medicines and the reasons for this practice are as shown in Table 2. For hospital participants, prior to the visit, the minority, 30 (25.0\%), used herbal medicines for their current sickness, while the majority of herbal clinic patrons, 81 (67.5\%), used orthodox medicine before visiting the herbal clinic. For all the participants, only $43(17.9 \%)$ were concurrently using both herbal and orthodox medicines. The orthodox doctors or herbal practitioners did not bother to ask the majority of these participants, 27 (62.8\%), if they were concurrently using both orthodox and herbal medicines.
For those concurrently using both orthodox and herbal medicines, the majority, 25 (58.1\%), do not intend to stop that practice, with a further 11 (25.8) not sure of stopping or continuing. The top two reasons for concurrent use of herbal and orthodox medicines were the following: both medicine types work together for the management of the condition, 10 (25.0\%), and the combination of both forms of medicines was more effective in treating the prevailing disease condition, 9 (23.1\%).

3.3. Reasons for Participants' First Choice of Medicines When Sick. The majority of hospital attendees, 65 (54.2\%), and 59 of the herbal clinic attendees (49.2\%) would first opt for orthodox medications when sick. The top three reasons why hospital attendees would first opt for orthodox medicines were the following: the medicines being more effective (27.9\%), better studied, and approved (22.1\%) and clearer dosage $(14.7 \%)$. For herbal clinic attendees, their top three 
TABLE 2: Concurrent use of both herbal and orthodox medicines.

\begin{tabular}{|c|c|c|c|}
\hline Variable & Subgroup & Frequency & Percentage \\
\hline \multirow{2}{*}{$\begin{array}{l}\text { Have you ever used herbal medicine (HM) for current sickness } \\
\text { before coming to the hospital? }(n=120)\end{array}$} & Yes & 30 & 25.0 \\
\hline & No & 86 & 71.7 \\
\hline \multirow{2}{*}{$\begin{array}{l}\text { Have you ever used orthodox medicine }(\mathrm{OM}) \text { for current } \\
\text { sickness before coming to the herbal clinic? }(n=120)\end{array}$} & Yes & 81 & 67.5 \\
\hline & No & 37 & 30.8 \\
\hline \multirow{2}{*}{ Are you concurrently using HM and OM for current ailment? } & Yes & 43 & 17.9 \\
\hline & No & 187 & 77.9 \\
\hline \multirow{2}{*}{$\begin{array}{l}\text { Did orthodox doctor or herbal doctor ask you of current usage } \\
\text { of HM and OM? }(n=43)\end{array}$} & Yes & 12 & 27.9 \\
\hline & No & 27 & 62.8 \\
\hline \multirow{3}{*}{ Do you intend stopping concurrent use of $\mathrm{HM}$ and $\mathrm{OM}$ ? } & Yes & 7 & 16.3 \\
\hline & No & 25 & 58.1 \\
\hline & Not sure & 11 & 25.6 \\
\hline \multirow{6}{*}{$\begin{array}{l}\text { What are the reasons for concurrent use of HM and OM? } \\
(n=39)\end{array}$} & $\begin{array}{l}\text { Both work together to manage my } \\
\text { condition }\end{array}$ & 10 & 25.6 \\
\hline & $\begin{array}{l}\text { Make me more comfortable about } \\
\text { managing my condition }\end{array}$ & 2 & 5.1 \\
\hline & More effective in treating diseases & 9 & 23.1 \\
\hline & Others & 4 & 10.3 \\
\hline & Quicken recovery & 7 & 17.9 \\
\hline & Treatment cost is lower & 7 & 17.9 \\
\hline
\end{tabular}

reasons were as follows: easy accessibility of orthodox medicines (18.5\%), faster curing (15.4\%), and clearer dosage (13.8\%). The minority of both hospital and herbal clinic attendees, 42 (35.0\%), would opt for herbal medicines as the first choice of medication when unwell. The top three reasons why patrons of hospitals would first opt for herbal medicines when sick were as follows: they were more effective $(28.8 \%)$, they cure faster (15.2\%), and they bring complete cure $(10.6 \%)$. For the herbal clinic attendees, herbal medicines being more effective (22.1\%), having no or lesser side effects (13.2\%), curing completely (13.2\%), and curing faster $(13.2 \%)$ were their main reasons for choosing herbal medicines over orthodox medicines. Table 3 shows the type of medications respondents would first opt for whenever they fall sick and the reasons for their choices.

Nine variables describing the sociodemographic characteristics of the respondents, namely, sex, age, religion, location of stay when growing up, marital status, educational level, employment status, income level, and the type of health facility, whether it was an orthodox hospital or a herbal clinic, were analyzed against concurrent use of herbal and orthodox medicines using binary logistic regression (Table 4). Age of the respondents was the only factor that was significantly associated with the concurrent use of herbs and orthodox medicines $(p=0.015)$ with persons less than 30 years old almost 2.4 times more likely to co-use the two types of medicines (OR, 2.381; 95\% CI, 1.183-4.793). Although more persons who sought healthcare services from hospitals concurrently used both herbal and orthodox medicines more than those at herbal clinics (20.5\% versus $16.9 \%)$, the difference was not statistically significant.

\section{Discussion}

Technological advancement had led to better understanding of diseases which had led to development of pure chemicals which have been used to formulate orthodox medicines mostly used in modern health facilities across the world. It would have been expected that crude natural products or alternative medicines would see a decline in usage, but studies have shown a rather increased usage across the world [20-23]. Despite the increasing patronage of herbal products across the world, this study found that the majority was of both hospital clients $(54.2 \%)$, while most (49.2\%) of herbal clinic attendees opted for orthodox medicines as their first choice of medication when unwell. A study in communities in Orlu Local Government Area in the Imo state and Abuja both in Nigeria found that $70.4 \%$ and $86.3 \%$, respectively, opted first for orthodox medicines $[17,18]$. With increased availability of orthodox medicines and the increasing level of interest in herbal medicines, there is a tendency for both forms of drugs, being concurrently used or one form is used prior to the use of the other one. This study found that two-thirds of patients attending herbal clinics used orthodox medicines prior to their visit to the facilities, while only a quarter of hospital attendees used herbal medicines preceding their visits. What could have accounted for the high level of orthodox medication among the herbal clinic attendees and the lower level of herbal product usage by the hospital attendees is that orthodox medicines are more accessible in a city as Tamale, where over-the-counter medicine sellers and pharmacies are within walking distance of homes unlike the herbal shops. Accessibility to orthodox medicines was the most cited 
TABLE 3: Participants' first choice of medicines when sick and the reasons for the choices.

\begin{tabular}{|c|c|c|c|c|c|}
\hline \multirow[t]{2}{*}{ Variable } & \multirow[t]{2}{*}{ Subgroups } & \multicolumn{2}{|c|}{ Hospital attendee } & \multicolumn{2}{|c|}{$\begin{array}{l}\text { Herbal clinic } \\
\text { attendee }\end{array}$} \\
\hline & & Frequency & Percentage & Frequency & Percentage \\
\hline \multirow{3}{*}{ First medication choice when sick } & Orthodox & 65 & 54.2 & 59 & 49.2 \\
\hline & Herbal & 42 & 35.0 & 42 & 35.0 \\
\hline & Uncertain & 13 & 10.8 & 19 & 15.8 \\
\hline \multirow{14}{*}{$\begin{array}{l}\text { Reasons for choosing orthodox medicine first }(n \\
\text { Hosp. }=68 ; n \text { herb }=65)\end{array}$} & Accessible & 5 & 7.4 & 12 & 18.5 \\
\hline & Clear dosage & 10 & 14.7 & 9 & 13.8 \\
\hline & Well studied and approved & 15 & 22.1 & 8 & 12.3 \\
\hline & More effective & 19 & 27.9 & 4 & 6.2 \\
\hline & $\begin{array}{l}\text { Condition requires medical } \\
\text { care }\end{array}$ & 4 & 5.9 & NA & NA \\
\hline & Safer & 7 & 10.3 & 6 & 9.2 \\
\hline & More confidence in OM & 3 & 4.4 & NA & NA \\
\hline & Recommended & 2 & 2.9 & NA & NA \\
\hline & Others & 3 & 4.4 & 5 & 7.7 \\
\hline & Cures faster & NA & NA & 10 & 15.4 \\
\hline & Easy and convenient & NA & NA & 3 & 4.6 \\
\hline & Personal preference & NA & NA & 2 & 3.1 \\
\hline & Prepared hygienically & NA & NA & 4 & 6.2 \\
\hline & Variety of forms & NA & NA & 2 & 3.1 \\
\hline \multirow{12}{*}{$\begin{array}{l}\text { Reasons for choosing herbal medicine first ( } n \\
\text { hosp. }=66 ; n \text { herb }=68)\end{array}$} & Accessibility & 4 & 6.1 & 3 & 4.4 \\
\hline & Affordability & 6 & 9.1 & 7 & 10.3 \\
\hline & Heritage & 6 & 9.1 & NA & NA \\
\hline & More effective & 19 & 28.8 & 15 & 22.1 \\
\hline & No or lesser side effects & 6 & 9.1 & 9 & 13.2 \\
\hline & $\begin{array}{c}\mathrm{OM} \text { is unable to manage all } \\
\text { diseases }\end{array}$ & 2 & 3.0 & & \\
\hline & Cures completely & 7 & 10.6 & 9 & 13.2 \\
\hline & Cures faster & 10 & 15.2 & 9 & 13.2 \\
\hline & Natural & 2 & 3.0 & 5 & 7.4 \\
\hline & Less complicated & NA & NA & 2 & 2.9 \\
\hline & $\begin{array}{l}\text { Personally like herbal } \\
\text { medicines }\end{array}$ & NA & NA & 4 & 5.9 \\
\hline & Others & 4 & 6.1 & 5 & 7.4 \\
\hline
\end{tabular}

NB. $n$ Herb $=$ respondents from the herbal clinics, $n$ hosp. $=$ respondents from the hospitals, and NA $=$ not applicable.

reason by herbal clinic attendees for opting for this form of therapy as first choice when sick. Although it is unclear if the patrons of the herbal clinics who had used orthodox medicines prior to their visit got them based on a physician's prescription or self-medication and even whether they administered the drugs using the right dosage regimen, their decision to seek healthcare at herbal clinics could possibly be due to their lack of satisfaction with the orthodox medications. This assertion is supported by the results of this study which found that both hospital and herbal clinic attendees had their topmost reason for opting for herbal medicines being that herbal medicines are more effective than orthodox medicines. Lack of satisfaction with orthodox medicines had also been found to be a major reason for people opting for herbal medicines in one study in the USA [20]. This study recorded about a fifth (17.9\%) of respondents concurrently using both herbal and orthodox medicines which is lower than results from countries such as Nigeria, Kenya, and Norway where between $25 \%$ and $69.4 \%$ concurrently used both herbal and orthodox medicines [15$18,24]$. The possible reason for the lower rate in this study could be because the responses given by the participants were in relation to the concurrent use of both forms of medication for the ailment for which they had gone to seek healthcare but most other studies questioned respondents if they had ever concurrently used herbal and orthodox medicines. For more than half of respondents in this study who concurrently use HM and OM not intending to stop the 
TABLE 4: Sociodemographic predictors of concurrent usage of orthodox and herbal medicines.

\begin{tabular}{|c|c|c|c|c|c|c|c|}
\hline \multirow[t]{2}{*}{ Variable } & \multirow[t]{2}{*}{ Subgroup } & \multicolumn{3}{|c|}{$\begin{array}{c}\text { Have you ever used herbal and } \\
\text { orthodox medicines } \\
\text { concurrently? }\end{array}$} & \multirow{2}{*}{$\begin{array}{l}\text { \% of concurrent } \\
\text { users of HM and } \\
\text { OM }\end{array}$} & \multirow[t]{2}{*}{$p$ value } & \multirow[t]{2}{*}{$\begin{array}{c}\text { Crude odd ratio (95\% } \\
\text { CI) }\end{array}$} \\
\hline & & Yes & No & Total number & & & \\
\hline \multirow{2}{*}{ Sex } & Female & 23 & 98 & 121 & 19.0 & 0.925 & $1.033(0.531-2.008)$ \\
\hline & Male $e^{\text {Ref }}$ & 20 & 88 & 108 & 18.5 & & \\
\hline \multirow{2}{*}{ Age } & $<30$ & 29 & 87 & 116 & 25.0 & $0.015^{*}$ & $2.381(1.183-4.793)$ \\
\hline & $>30^{\text {Ref }}$ & 14 & 100 & 114 & 12.3 & & \\
\hline \multirow{2}{*}{ Religion } & Christianity & 13 & 67 & 80 & 16.3 & 0.46 & $0.763(0.373-1.563)$ \\
\hline & Islam $^{\text {Ref }}$ & 29 & 116 & 145 & 20.0 & & \\
\hline \multirow{2}{*}{ Location } & Urban $^{\text {Ref }}$ & 21 & 96 & 117 & 17.9 & 0.768 & $1.105(0.569-2.145)$ \\
\hline & Rural & 22 & 91 & 113 & 19.5 & & \\
\hline \multirow{3}{*}{ Marital status } & Single ${ }^{\text {Ref }}$ & 20 & 70 & 90 & 22.2 & & \\
\hline & Currently married & 20 & 84 & 104 & 19.2 & 0.082 & $0.259(0.057-1.185)$ \\
\hline & Ever been married & 2 & 27 & 29 & 6.9 & 0.608 & $0.833(0.415-1.672)$ \\
\hline \multirow{4}{*}{$\begin{array}{l}\text { Educational } \\
\text { status }\end{array}$} & $\begin{array}{l}\text { No formal } \\
\text { education }\end{array}$ & 8 & 61 & 69 & 11.6 & 0.390 & $0.656(0250-1.718)$ \\
\hline & Basic & 3 & 21 & 24 & 12.5 & 0.628 & $0.714(0.183-2.781)$ \\
\hline & Secondary & 12 & 38 & 50 & 24.0 & 0.318 & $1.579(0.644-3.374)$ \\
\hline & Tertiary $^{\text {Ref }}$ & 12 & 60 & 72 & 16.7 & & \\
\hline \multirow{3}{*}{$\begin{array}{l}\text { Employment } \\
\text { status }^{\text {a }}\end{array}$} & Unemployed $^{\text {Ref }}$ & 23 & 76 & 99 & 23.2 & & \\
\hline & Self-employed & 15 & 69 & 84 & 17.9 & 0.373 & $0.718(0.347-1487)$ \\
\hline & Employed & 5 & 41 & 46 & 10.9 & 0.086 & $0.403(0.143-1.139)$ \\
\hline \multirow[b]{2}{*}{ Income status } & Low income $e^{\text {Ref }}$ & 35 & 153 & 185 & 18.6 & & \\
\hline & $\begin{array}{l}\text { Middle to high } \\
\text { income }\end{array}$ & 8 & 32 & 40 & 20.0 & 0.839 & $1.093(0.464-2.576)$ \\
\hline \multirow{2}{*}{$\begin{array}{l}\text { Place of seeking } \\
\text { health }\end{array}$} & Hospital $^{\text {Ref }}$ & 23 & 89 & 112 & 20.5 & & \\
\hline & Herbal clinic & 20 & 98 & 118 & 16.9 & 0.486 & $0.790(0.406-1.535)$ \\
\hline
\end{tabular}

Ref: reference variable, ${ }^{*}$ statistically significant, and ${ }^{\mathrm{a}}$ Unemployed, students, housewives, and retirees were grouped as unemployed, while private and public sector workers were considered as employed.

practice and almost two-thirds of their physicians or herbal practitioners not asking them of their concurrent use of these two types of medicines gives some cause to worry. Residents in Tamale who seek healthcare services either in the hospitals or in the herbal clinics are therefore invariably exposed to greater chances of suffering the negative effects of drug-herb interactions. The fact that most respondents also stated that concurrent use of herbal and orthodox medicines is better and a more effective way of treating their conditions brings to the fore the need for greater education to lessen the consequences of drug-herb interactions. Several studies in Nigeria and Norway found an association between concurrent use of herbal and orthodox medicines and several sociodemographic characteristics including age, sex, level of education, and income level [15-17]. This study however found age of respondents as the only factor associated with the concurrent use of herbal and orthodox medicines with individuals younger than 30 almost 2.4 times more likely to combine the two forms of drugs than those older than 30 years. This is contrary to studies by Djuv et al., (2013), Duru et al., (2016), and Githinji (2016) who found that concurrent usage of herbal and orthodox medicines increases with age $[16,17,24]$. The reason for the differences based on age could be that persons younger than 30 years in this study were more reluctant to seek healthcare services when sick, would self-medicate with all forms of drugs, and would only visit healthcare facilities when the situations become unbearable. A study in Brazil also showed that persons younger than 30 years significantly self-medicate [25]. The concurrent use of herbal and orthodox medicines by persons who attend hospitals and other orthodox health facilities is well documented [15-18] but not much can be found about the situation for those who attend herbal clinics. A study in the Githunguri Division of Kiambu Count in Kenya among patrons of herbal clinics also showed a high level (42.5\%) of orthodox medicines, a number higher than the $20.5 \%$ reported in this study [24]. The variation in the result $(42.5 \%$ versus $20.5 \%$ ) could be attributed to the difference in location since the Githunguri division is a rural area, while Tamale is a city. Access to orthodox medicines is more controlled in cities than rural areas of Ghana where drug peddlers move around to illegally dispense orthodox medicines; hence rural 
dwellers easily acquire these medicines which they sometimes concurrently take with the herbal preparations [26]. Millions of people across the world would continue to depend on herbal medicines for the management of their health conditions [27] so the patronage of the increasing number of herbal clinics in Ghana would continue. With this study showing that the place of seeking healthcare services did not have any association with concurrent use of HM and $\mathrm{OM}$, it is important that besides orthodox healthcare practitioners, herbal medicine practitioners should also be sensitized to be interested in the drug history of their clientele and then educate them on the dangers of taking these forms of medications together. Although, this is possibly the first study in Ghana which assessed the concurrent use of OM and $\mathrm{HM}$ among patrons of orthodox medical practice centres and herbal clinics, several limitations could affect the adequacy and generalized interpretation of the results of this study. Firstly, the use of self-administered questionnaire in some cases rather than interviews for all makes verification of the answers provided by the respondents difficult. Again, some respondents could neither read nor write which requires a translation into a language the respondents understand. Errors of misinterpretation and recording of responses could also have affected the results. However, the results from this study should serve as a starting point for a nationwide study on the use of concurrent use of HM and OM among patrons of herbal clinics and how significant the level of this habit is when compared to patrons of orthodox medical systems.

\section{Conclusion}

Prevalence of the concurrent use of herbal and orthodox medicines in this study is low but when sick, almost half of respondents would opt for orthodox medicines. All the sociodemographic characteristics of respondents except the age had no association with respondents' concurrent usage of herbal and orthodox medicines. Patients less than 30 years were almost 2.4 times more likely to concurrently use both herbal and orthodox medicines than those above 30 years but the place of seeking healthcare system, whether orthodox medical systems or herbal clinics, had no association with this habit. Belief that both herbal medicines and orthodox medicines work together to manage an ailment is the main reason for those who use both forms of medications.

\section{Ethical Approval}

Prior approval for this study and the procedures was obtained from the Ethics Committee of the School of Medicine and Health Sciences of the University for Development Studies.

\section{Disclosure}

Participants were only interacted with following granting of permission by the heads of various institutions mentioned in the study. Data was collected from participants only after they had verbally given free and informed consent to take part in the study. Funding was by the authors.

\section{Conflicts of Interest}

The authors declare that they have no conflicts of interest.

\section{Authors' Contributions}

Evans Paul Kwame Ameade, Mohammed Ibrahim, HalimatuSadia Ibrahim, and Rabiatu Hamisu Habib conceived the idea and designed the questionnaire. Mohammed Ibrahim, Halimatu-Sadia Ibrahim, and Rabiatu Hamisu Habib collected the data. Evans Paul Kwame Ameade analyzed the data. Evans Paul Kwame Ameade, Mohammed Ibrahim, and Stephen Yao Gbedema did the drafting of the manuscript.

\section{References}

[1] M. A. Kuhn, "Herbal remedies: drug-herb interactions.," Critical Care Nurse, vol. 22, no. 2, pp. 22-34, 2002.

[2] K. P. Osemene, A. A. Elujoba, and M. O. Ilori, "A comparative assessment of herbal and orthodox medicines in Nigeria," Research Journal of Medical Sciences, vol. 5, no. 5, pp. 280-285, 2011.

[3] M. F. Mahomoodally, "Traditional medicines in Africa: an appraisal of ten potent African medicinal plants," EvidenceBased Complementary and Alternative Medicine, vol. 2013, Article ID 617459, 14 pages, 2013.

[4] K. Chan and L. Cheung, Interactions between Chinese herbal medicinal products and orthodox drugs, CRC Press, 2000.

[5] P. A. G. M. De Smet, "The role of plant-derived drugs and herbal medicines in healthcare," Drugs, vol. 54, no. 6, pp. 801-840, 1997.

[6] P. J. Houghton, "Synergy and polyvalence: paradigms to explain the activity of herbal products," Evaluation of herbal medicinal products, pp. 85-94, 2009.

[7] World Health Organization. WHO traditional medicine strategy 2002-2005.

[8] S. Bent, "Herbal medicine in the United States: review of efficacy, safety, and regulation: grand Rounds at University of California, San Francisco Medical Center," Journal of General Internal Medicine, vol. 23, no. 6, pp. 854-859, 2008.

[9] A. Molassiotis, P. Fernandez-Ortega, D. Pud et al., "Use of complementary and alternative medicine in cancer patients: a European survey," Annals of Oncology, vol. 16, no. 4, pp. 655663, 2005.

[10] L. Howell, K. Kochhar, R. M. Saywell Jr. et al., "Use of herbal remedies by Hispanic patients: do they inform their physician?" Journal of the American Board of Family Medicine, vol. 19, no. 6, pp. 566-578, 2006.

[11] K. Sekhri, S. Bhanwra, and R. Nandha, "Herbal products: a survey of students\&\#8217; perception and knowledge about their medicinal use," International Journal of Basic \& Clinical Pharmacology, vol. 2, no. 1, p. 71, 2013.

[12] E. P. K. Ameade, A. Amalba, G. K. Helegbe, and B. S. Mohammed, "Medical students' knowledge and attitude towards complementary and alternative medicine - A survey in Ghana," Journal of Traditional and Complementary Medicine, vol. 6, no. 3, pp. 230-236, 2016.

[13] J. Neustadt, "Herb-drug interactions: What clinicians need to know?” Integrative Med, pp. 16-26, 2006.

[14] Asare BE. Developments made in herbal medicine practice in Ghana. [Internet] Modern Ghana. 2016, [cited 9 January, 2018]. 
Available from: https://www.modernghana.com/news/594410/ developments-made-in-herbal-medicine-practice-in-ghana.html.

[15] P. A. MO, "Prevalence of concurrent use of herbal and synthetic medicines among outpatients in a mission hospital in Nigeria," International Journal of Drug Development and Research, 2009.

[16] A. Djuv, O. G. Nilsen, and A. Steinsbekk, "The co-use of conventional drugs and herbs among patients in Norwegian general practice: a cross-sectional study," BMC Complementary and Alternative Medicine, vol. 13, article 295, 2013.

[17] C. B. Duru, K. C. Diwe, K. A. Uwakwe et al., "Combined Orthodox and Traditional Medicine Use among Households in Orlu, Imo State, Nigeria: Prevalence and Determinants," World Journal of Preventive Medicine, vol. 4, no. 1, pp. 5-11, 2016.

[18] K. B. Mustapha, R. A. Kirim, J. A. Ibrahim, P. U. Onuche, and M. T. Bakare-Odunola, "Perception of use of herbal and orthodox medicines in parts of Abuja: A pilot study," Journal of Applied Pharmaceutical Science, vol. 6, no. 9, pp. 128-132, 2016.

[19] Ghana Statistical Service. 2010 Population and Housing Census. Summary of Final Results. Accra. 2012.

[20] J. A. Astin, "Why patients use alternative medicine: results of a national study," Journal of the American Medical Association, vol. 279, no. 19, pp. 1548-1553, 1998.

[21] A. Kilcoyne, P. Ambery, and D. O'Connor, Trade and production of herbal medicines and natural health products, vol. 3, Oxford University Press, ICS-UNIDO, Trieste, Italy, 2013.

[22] World Health Organization. WHO guidelines on safety monitoring of herbal medicines in pharmacovigilance systems. 2004. Geneva: World Health Organization. vii. [Internet]. 2015. [cited 26 January, 2017]. Available from: http://apps.who .int/medicinedocs/documents/s7148e/s7148e.pdf. Accessed 26 January 2017.

[23] N. Sahoo, P. Manchikanti, and S. Dey, "Herbal drugs: standards and regulation," Fitoterapia, vol. 81, no. 6, pp. 462-471, 2010.

[24] F. N. Githinji, Utilisation of herbal products and concomitant use with conventional medicine in Githunguri Division, Kiambu County [Doctoral, thesis], Doctoral dissertation, Kenya, Doctoral dissertation.

[25] M. G. C. da Silva, M. C. F. Soares, and A. L. Muccillo-Baisch, "Self-medication in university students from the city of Rio Grande, Brazil," BMC Public Health, vol. 12, article 339, 2012.

[26] Baidoo FA. Illegal peddling of drugs poses health risk. [Internet]. 2014 [cited 9 January, 2018]. Available from: https://www .graphic.com.gh/news/health/illegal-peddling-of-drugs-poseshealth-risk.html.

[27] C. Anquez-Traxler, "The legal and regulatory framework of herbal medicinal products in the European Union: A focus on the traditional herbal medicines category," Drug Information Journal, vol. 45, no. 1, pp. 15-23, 2011. 


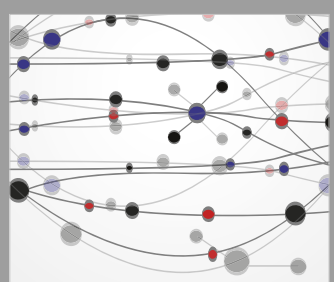

The Scientific World Journal
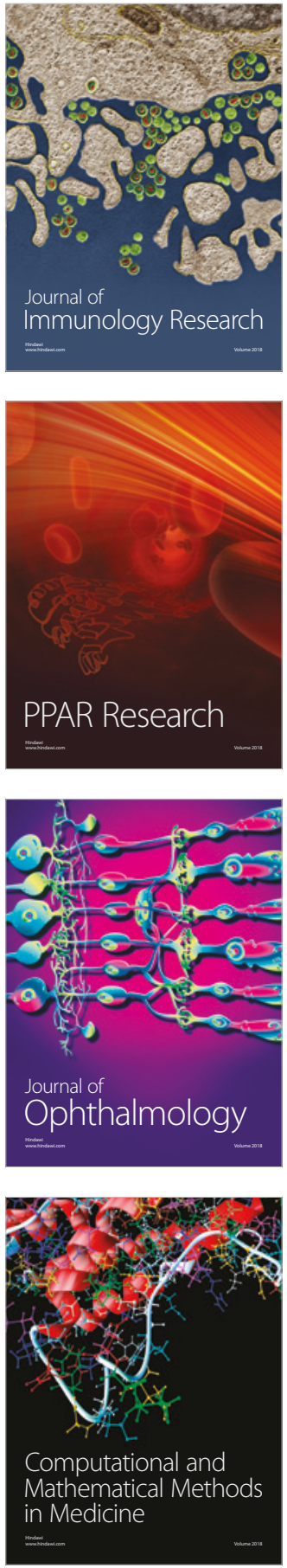

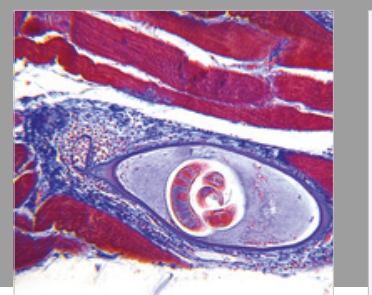

Gastroenterology Research and Practice

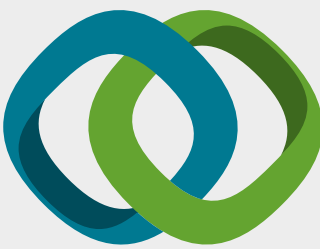

\section{Hindawi}

Submit your manuscripts at

www.hindawi.com
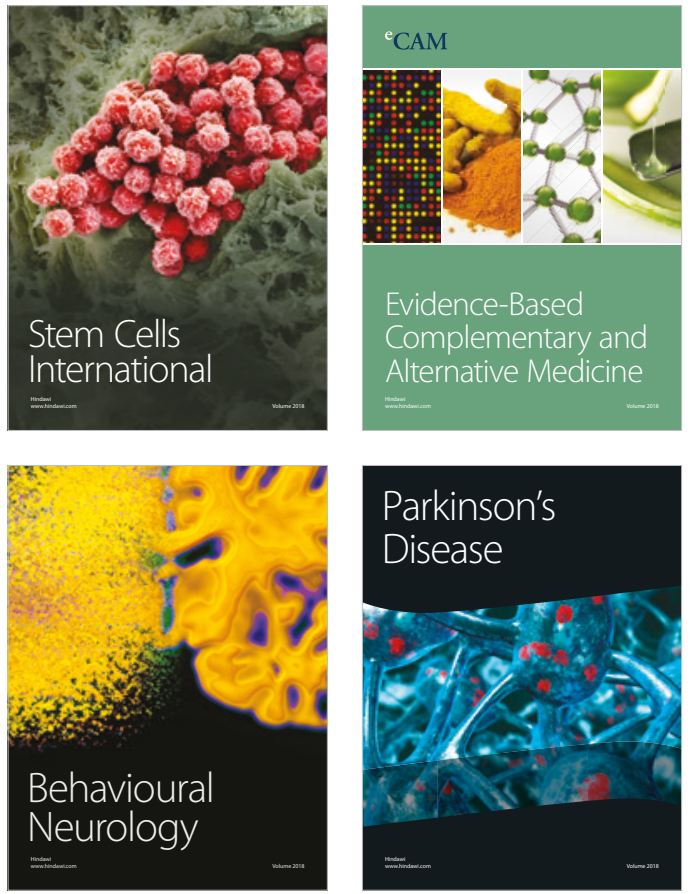

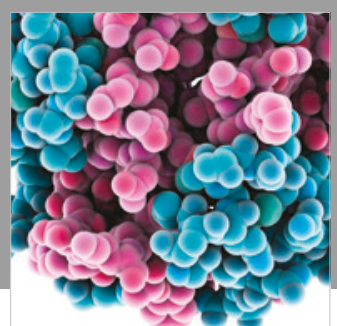

ournal of

Diabetes Research

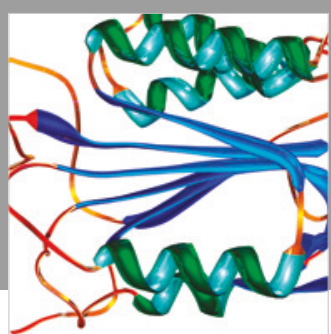

Disease Markers
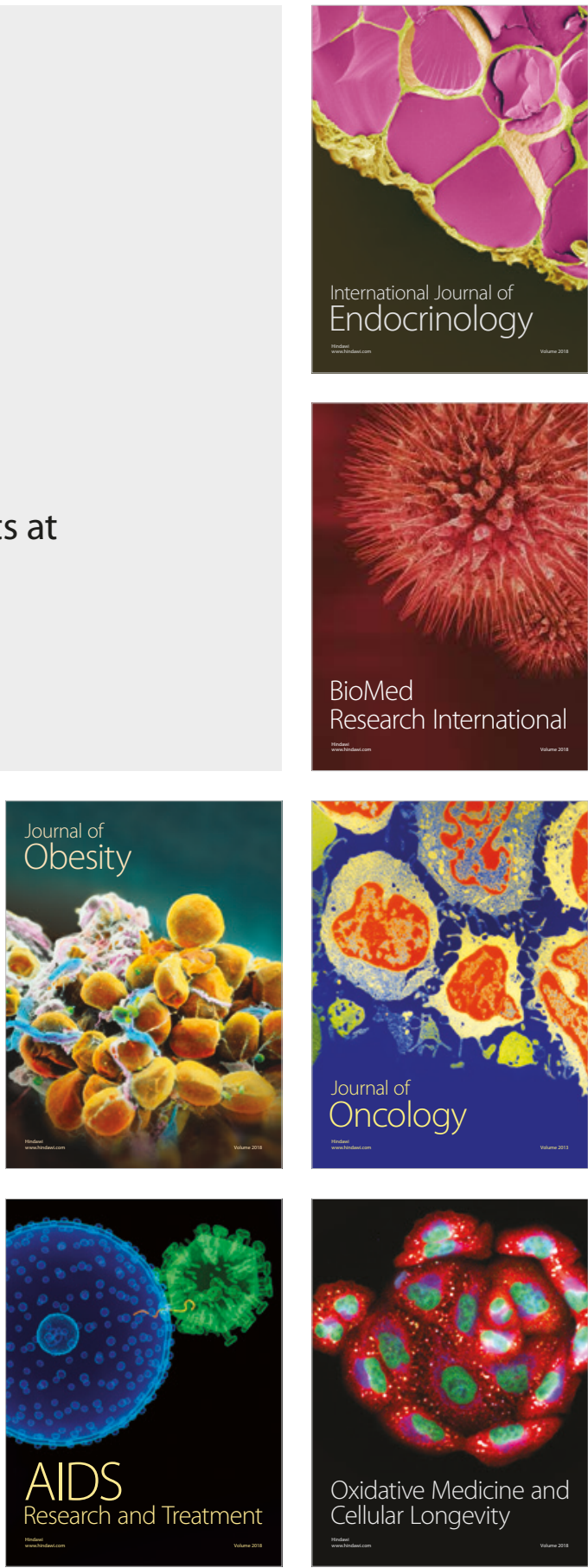